\title{
Risk Factors Predicting the Successful Function and Use of Autogenous Arteriovenous Fistulae for Hemodialysis
}

\author{
Engin Usta ${ }^{1}$ Raoof Elkrinawi ${ }^{1}$ Shahriar Salehi-Gilani ${ }^{1}$ Sara Adili ${ }^{1}$ Thorsten Sonnentag ${ }^{2}$ \\ Mark Alscher ${ }^{2}$ Ferruh Artunc $^{3}$ Ulrich Franke ${ }^{1}$
}

${ }^{1}$ Department of Cardiac and Vascular Surgery, Robert Bosch Hospital, Stuttgart, Germany

${ }^{2}$ Division of General Internal Medicine and Nephrology, Department of Internal Medicine, Robert Bosch Hospital, Stuttgart, Germany

${ }^{3}$ Section of Nephrology and Hypertension, Department of Internal

Medicine IV, Tübingen University Hospital, Tübingen, Germany

\begin{abstract}
Address for correspondence Engin Usta, MD, Department of Cardiac and Vascular Surgery, Robert Bosch Hospital, Auerbachstrasse 110, Stuttgart 70376, Germany (e-mail: engin.usta@gmx.de).
\end{abstract}

Thorac Cardiovasc Surg 2013;61:438-444.

\begin{abstract}
Background For patients with end-stage renal failure hemodialysis with an autogenous arteriovenous fistula (AVF) has proven to be the ideal vascular access.

Objective The aim of this study is to discover potential predictors of a well-functioning hemodialysis fistula.

Methods From December 2009 to March 2011, 80 patients undergoing first time AVF creation were enrolled in our retrospective study. We analyzed pre- and postoperative vessel diameters and flow characteristics gained by duplex ultrasonography (DUS) and intraoperative ultrasound transit-time flow measurements regarding intraoperative blood flow and pulsatility index (PI). Follow-up was defined until the end of the first month with regular hemodialysis, 10 weeks after AVF creation. We performed statistical analyses by employing Spearman correlation, $t$ test, analysis of variance, $X^{2}$ test, and receiver operating characteristics (ROC).

Results At the end of the follow-up, 62 patients (78\%) featured functioning AVFs and 18 patients (22\%) featured nonfunctioning AVFs. Factors influencing AVF function were radial artery diameter $\left(X^{2}=5.23, p=0.02\right)$, intraoperative flow $\left(x^{2}=7.09, p=0.01\right)$, intraoperative $\mathrm{PI}\left(\mathrm{X}^{2}=6.5, p=0.01\right)$, and postoperative flow $\left(\mathrm{X}^{2}=16.29, p=0.01\right)$. According to the ROC analyses, we could develop cut-off values for predicting an ideal

\section{Keywords}

- vascular science

- shunts

- peripheral vascular disease

- peripheral arteries AVF function: radial artery diameter more than $2.3 \mathrm{~mm}$, cephalic vein diameter more than $2.7 \mathrm{~mm}$, intraoperative mean flow more than $113 \mathrm{~mL} / \mathrm{min}$, PI less than 1.4 , and postoperative mean flow more than $160 \mathrm{~mL} / \mathrm{min}$.

Conclusion Intraoperative ultrasound transit-time flow measurements gained at surgery and postoperative follow-up with DUS can help identify AVFs that are unlikely to function and therefore need early intervention.
\end{abstract}

received

February 26, 2012

accepted after revision

April 11, 2012

published online

November 20, 2012 (c) 2013 Georg Thieme Verlag KG

Stuttgart · New York
DOI http://dx.doi.org/

10.1055/s-0032-1321953. ISSN 0171-6425. 


\section{Introduction}

Autogenous arteriovenous fistula (AVF) is the primary and best choice for vascular access in a chronic hemodialysis patient. ${ }^{1,2}$ When an AVF successfully matures after the surgical creation, it may work for years with a low risk of complications. The most common problem with AVFs is the lack of maturation, leading to inability to access the fistula or thrombosis. Nonmaturation depends not solely on the quality and size of the vessels, but also on the ability of vessel adaptation induced by the augmented blood flow volumes. Recently, several duplex-derived criteria have been developed. These show a favorable effect on AVFs by using well-sized radial arteries and cephalic veins. ${ }^{3,4}$ Therefore, preoperative assessment of the arm blood vessel characteristics with definition of suitable vessels emerges to an indispensable tool.

We propose that routine completion of duplex ultrasound (DUS) imaging during AVF creation can provide accurate hemodynamic characterization of early access work, predict access patency, and allow detection of nonfunctioning conduits for remedial intervention. This work should enlighten if positive correlations between the preoperative duplex-gained vessel data and intraoperative AVF blood flow and pulsatility index (PI) exists. The analyses should allow to develop cut-off values.

Data of this study were collected retrospectively. Followup finished after 4 months with regular hemodialysis three times a week. We interpreted the AVF as functioning for data analysis.

\section{Methods}

\section{Patient Characteristics}

From December 2009 to March 2011, we performed AVF construction in 80 patients with end-stage renal failure (53 men, 27 women; mean age 69 years) at our institution. The patients gave their informed consent before surgery. This study was approved by the Ethics Committee of the
Robert Bosch Hospital, Stuttgart, Germany. Inclusion criteria were new hemodialysis patients receiving first time AVF and willing to complete the follow-up. The demographic data of the patients are presented in -Table $\mathbf{1}$.

All patients were regularly seen by the nephrologists and the decision to start dialysis treatment was made on the severity of worsening of renal function. At enrolment, patients were diagnosed with stage $\mathrm{V}$ of chronic kidney disease (CKD) according to the working list of the National Kidney Foundation's Kidney Disease Outcomes Quality Initiative. ${ }^{5}$

The common causes of CKD among the patients included in this study were diabetes mellitus, hypertension, and glomerulonephritis. The enrolled patients featured accompanying diseases such as diabetes mellitus (65\%), hypertension (70\%), and coronary heart disease (20\%).

\section{Patient Cohorts}

The patients enrolled into this study were categorized into two groups. Depending on the clinical end point, AVF function during follow-up period was arranged either in the functioning or nonfunctioning group as depicted in -Tables $\mathbf{1}$ to $\mathbf{4}$.

\section{Preoperative Angiological Evaluation}

The construction of an AVF between the radial artery and the cephalic vein was planned for all patients. Routinely, all patients underwent preoperative clinical and noninvasive angiological testing that included arterial and central venous Doppler waveforms, radial artery diameter measurements (luminal diameter), and superficial vein mapping (with and without a tourniquet) by the attending vascular surgeon. The radial artery was palpated at the wrist before examination with DUS to mark the direction and exact position of the vessel. Further, a normal Allen test on the chosen side was compulsory.

DUS was performed by the vascular surgeon with a Siemens ACUSON Antares ultrasound system equipped with a VF13-5 transducer probe (Siemens AG, Erlangen, Germany) based on a standardized protocol. A two-dimensional linear

Table 1 Summary of the demographic data of patients in the functioning or nonfunctioning AVF group

\begin{tabular}{|c|c|c|c|c|}
\hline Variable & $\begin{array}{l}\text { Total patients } \\
(n=80)\end{array}$ & $\begin{array}{l}\text { Group functioning } \\
\text { AVF }(n=62)\end{array}$ & $\begin{array}{l}\text { Group nonfunctioning } \\
\text { AVF }(n=18)\end{array}$ & $p$ value \\
\hline Age, y, mean \pm SEM & $69 \pm 1$ & $68 \pm 2$ & $73 \pm 2$ & 0.09 \\
\hline \multicolumn{5}{|l|}{ Gender } \\
\hline Male & 50 & 42 & 8 & 0.06 \\
\hline Female & 26 & 16 & 10 & \\
\hline Body mass index, $\mathrm{kg} / \mathrm{m}^{2}$, mean $\pm \mathrm{SEM}$ & $27 \pm 1$ & $28 \pm 1$ & $27 \pm 1$ & 0.61 \\
\hline \multicolumn{5}{|l|}{ Comorbidities, $n(\%)$} \\
\hline Diabetes mellitus & $52(65)$ & $41(66)$ & $11(61)$ & 0.75 \\
\hline Hypertensive disease & $56(70)$ & $44(71)$ & $12(67)$ & 0.76 \\
\hline Coronary artery disease & $16(20)$ & $13(21)$ & $3(17)$ & 0.71 \\
\hline
\end{tabular}

Abbreviations: AVF, arteriovenous fistula; SEM, standard error of mean; y, years.

Note: The significances between both groups were calculated employing $t$ test with Welch Correction. Considering the demographic data and comorbidities of the patients, only the variable age is significantly different, with older patients in the nonfunctioning group. 
Table 2 Pre- and intraoperative vessel parameters

\begin{tabular}{|l|l|l|l|l|l|}
\hline Variable & $\begin{array}{l}\text { Total patients } \\
(\boldsymbol{n}=\mathbf{8 0})\end{array}$ & $\begin{array}{l}\text { Group functioning } \\
\text { AVF }(\boldsymbol{n}=\mathbf{6 2})\end{array}$ & $\begin{array}{l}\text { Group nonfunctioning } \\
\text { AVF }(\boldsymbol{n}=\mathbf{1 8})\end{array}$ & $\mathrm{X}^{2}$ & $p$ value \\
\hline $\begin{array}{l}\text { Preoperative diameter radial } \\
\text { artery, mm, mean } \pm \text { SEM }\end{array}$ & $2.4 \pm 0.1$ & $2.5 \pm 0.1$ & $2.19 \pm 0.1$ & 5.23 & 0.01 \\
\hline $\begin{array}{l}\text { Preoperative diameter cephalic } \\
\text { vein, mm, mean } \pm \text { SEM }\end{array}$ & $3.1 \pm 0.1$ & $3.2 \pm 0.1$ & $2.8 \pm 0.8$ & 3.7 & 0.07 \\
\hline $\begin{array}{l}\text { Intraoperative AVF flow, } \\
\mathrm{mL} / \text { min, mean } \pm \text { SEM }\end{array}$ & $180 \pm 15$ & $201 \pm 18$ & $111 \pm 17$ & 7.09 & 0.01 \\
\hline $\begin{array}{l}\text { Intraoperative AVF PI, } \\
\text { mean } \pm \text { SEM }\end{array}$ & $0.9 \pm 0.1$ & $0.77 \pm 0.1$ & $1.21 \pm 0.2$ & 6.5 & 0.04 \\
\hline $\begin{array}{l}\text { Postoperative AVF flow, } \\
\mathrm{mL} / \text { min, mean } \pm \text { SEM }\end{array}$ & $327 \pm 26$ & $401 \pm 27$ & $87 \pm 24$ & 16.29 & 0.01 \\
\hline
\end{tabular}

Abbreviations: AVF, arteriovenous fistula; PI, pulsating index; SEM, standard error of mean.

Note: Depicted diameters refer to intraluminal values. All variables featured significant influences on the AVF function with the cephalic vein diameter, exceptionally. Data are expressed as mean \pm SEM.

Table 3 Calculation of Spearman correlation coefficient $(\rho)$ between two variables

\begin{tabular}{|l|l|l|l|}
\hline Variable & By variable & $\begin{array}{l}\text { Spearman correlation } \\
\text { coefficient }(\rho)\end{array}$ & $p$ value \\
\hline Intraoperative AVF flow & Preoperative radial artery diameter & 0.37 & 0.01 \\
\hline Intraoperative AVF PI & Preoperative radial artery diameter & -0.20 & 0.07 \\
\hline Postoperative AVF flow & Preoperative radial artery diameter & 0.25 & 0.03 \\
\hline Intraoperative AVF flow & Preoperative cephalic vein diameter & 0.36 & 0.01 \\
\hline Intraoperative AVF PI & Preoperative cephalic vein diameter & -0.16 & 0.17 \\
\hline Preoperative AVF flow & Preoperative cephalic vein diameter & 0.24 & 0.04 \\
\hline Preoperative AVF flow & Intraoperative AVF PI & -0.04 & 0.01 \\
\hline Intraoperative AVF flow & Intraoperative AVF PI & -0.04 & 0.01 \\
\hline
\end{tabular}

Abbreviations: AVF, arteriovenous fistula; PI, pulsating index.

Note: The highest correlations were found between intraoperative AVF flow and preoperative radial artery diameter, intraoperative AVF flow and preoperative cephalic vein diameter, intraoperative AVF flow and intraoperative PI, and postoperative AVF flow and intraoperative PI.

Table 4 Analyses of the ROC analyses

\begin{tabular}{|c|c|c|c|c|c|c|}
\hline Variable & Cut-off values & Specificity & Sensitivity & $\begin{array}{l}\text { Area under } \\
\text { the curve }\end{array}$ & $\begin{array}{l}95 \% \text { confidence } \\
\text { interval }\end{array}$ & $p$ value \\
\hline Preoperative diameter radial artery & $2.3 \mathrm{~mm}$ & 0.61 & 0.74 & 0.71 & $0.57-0.84$ & 0.01 \\
\hline Preoperative diameter cephalic vein & $2.7 \mathrm{~mm}$ & 0.56 & 0.77 & 0.67 & $0.52-0.83$ & 0.08 \\
\hline Intraoperative AVF flow & $113 \mathrm{~mL} / \mathrm{min}$ & 0.67 & 0.76 & 0.76 & $0.62-0.89$ & 0.03 \\
\hline Intraoperative AVF PI & 1.4 & 0.39 & 0.97 & 0.68 & $0.53-0.83$ & 0.02 \\
\hline Postoperative AVF flow & $160 \mathrm{~mL} / \mathrm{min}$ & 0.94 & 0.91 & 0.96 & $0.88-1.03$ & 0.01 \\
\hline
\end{tabular}

Abbreviations: AVF, arteriovenous fistula; PI, pulsating index; ROC, receiver operating characteristics.

Note: The highest values (e.g., high sensitivity) were revealed by intraoperative AVF flow, intraoperative AVF PI, and postoperative AVF flow. The diameter of the radial artery $(2.3 \mathrm{~mm})$ and cephalic vein $(2.7 \mathrm{~mm})$, intraoperative flow $(113 \mathrm{~mL} / \mathrm{min})$, intraoperative PI (1.4), and postoperative flow $(160 \mathrm{~mL} / \mathrm{min})$ were fundamentally predictive requirements for an optimal AVF function. 
electronic probe at 7.0 MHz, pulse wave Doppler at 5.0 MHz, and color Doppler at $5.0 \mathrm{MHz}$ were used. The angle of the emitted Doppler ultrasound wave from the probe was adjusted to 60 degrees to achieve the Doppler signal of the strongest intensity. The internal diameter of the vessel was measured using M-mode technique. Transverse examinations were made over the artery and the cross-sectional area of the artery was calculated. Time-averaged velocity (TAV) was calculated directly from a Doppler spectral waveform by the duplex scanner system. The volume flow was obtained from TAV and the cross-sectional surface area. Measurements were performed before AVF creation, and 2 days and 6 weeks after AVF creation.

\section{Operative Procedure}

All patients were scheduled for a primary AVF creation between the radial artery and cephalic vein. All the patients gave their informed consent before surgery. At our institution, two vascular surgeons (E.U. and S.S-G.) performed the arteriovenous access surgery as an anastomosis between the cephalic vein and radial artery-a so-called Bresica-Cimino shunt. ${ }^{6}$ The chosen anesthetic procedures were local anesthesia $(20 \%, n=16)$, regional axillary block $(60 \%, n=48)$, or general anesthesia $(20 \%, n=16)$; the last one for excessively anxious patients.

The radial artery and cephalic vein were exposed through a longitudinal or transverse incision of 4 to $5 \mathrm{~cm}$ proximal of the radial styloid process. After sufficient dissection, the cephalic vein was isolated, divided, and hydrodilated with heparinized saline. During the hydrodilatation, the continuity of the cephalic vein and any recognizable resistance changes were followed closely. For the standard arteriotomy, the radial artery was incised $10 \mathrm{~mm}$. The end-to-side, vein-to-artery anastomosis was performed with a running 8/0 Seralon polyamide suture (Serag-Wiessner KG, Naila, Germany).

\section{Intraoperative Flow Quantification}

AVF flow was measured 5 minutes after anastomosis completion. The systolic blood pressure was preserved between 100 and $120 \mathrm{~mm} \mathrm{Hg}$. The handheld 3- or 4-mm ultrasound transit-time flowprobe connected to a MediStim VeriQ System (MediStim ASA, Oslo, Norway) was placed to encircle the cephalic vein, approximately 5 to $10 \mathrm{~mm}$ behind the anastomosis. The following features were obtained during the measurements: (1) the mean flow as milliliters per minute and (2) the PI. PI was calculated by a device according to the relation PI = (PSV - MDV)/MV (PSV, peak systolic velocity; $\mathrm{MDV}$, minimum diastolic velocity; and MV, mean velocity).

\section{Anticoagulation}

Following exploration of the arteries and veins and before placing the clamp, 5,000 IE heparin was routinely administered intravenously to each patient during AVF creation. During the postoperative course, patients without a risk factor for thrombosis were just anticoagulated with a single dose of heparin, 5,000 IE/d subcutaneously. Otherwise, like in the case of three patients with atrial fibrillation subcutaneous heparin 5,000 IE was administered twice a day, and later as outdoor patients they were set on phenprocoumon with international normalized ratio values in the therapeutic range of 2 to $3 .^{7}$

\section{Maturation and Postoperative Follow-Up}

DUS of the AVF was performed before discharge from the hospital on the second postoperative day with a Siemens ACUSON Antares ${ }^{\mathrm{TM}}$ ultrasound system equipped with a VF135 transducer probe based on a standardized protocol by the vascular surgeon. The percent stenosis diameter was calculated as the relationship between the minimal luminal diameter at the stenosis site and the diameter of a nearby normal segment. A lumen reduction of $50 \%$ or greater was considered major stenosis. The flow rate of the fistula in milliliters per minute was estimated according to the following formula and considered normal when greater than $160 \mathrm{~mL} / \mathrm{min}$ :

$$
V=\pi r^{2} \times V_{\text {average }} \times 60
$$

where $V$ indicates flow in milliliters per minute; $r$, ray of the segment; $V_{\text {average, }}$ average of the speeds obtained in centimeters per second by DUS; and 60, correction factor.

Clinical criteria were used for detection of nonfunctioning AVFs. The inability to cannulate the AVF or to obtain sufficient dialysis blood flow of at least $250 \mathrm{~mL} / \mathrm{min}$ within 6 weeks with three sessions per week after fistula creation was indicator of a poorly functioning AVF, regardless of whether it is patent. Follow-up was defined until the end of the first month with regular hemodialysis, in other means 10 weeks after AVF creation. All patients with nonmaturating AVFs underwent duplex evaluation. These patients were screened from the brachial artery down to the radial artery via anastomosis and upward to the upper arm following the cephalic vein to detect stenosis or thrombosis.

\section{Statistical Analysis}

Patient characteristics and duplex parameters of functioning and nonfunctioning AVFs were compared with unpaired $t$ test with Welch correction and one-way analysis of variance with Bonferroni multiple comparison test as post hoc test. Further statistical analyses were performed with matched pairs including Spearman correlation coefficient, receiver operating characteristics (ROC), and $\mathrm{X}^{2}$ test using the JMP program (version 9, SAS Institute, Cary, North Carolina, United States). A $p$ value of less than 0.05 was considered to indicate a statistically significant difference. Numerical data are expressed as mean \pm standard deviation (SD).

\section{Results}

In the functioning group, 62 patients (78\%) presented with AVFs with a normal maturation. In the nonfunctioning group, 18 patients (22\%) featured 13 nonmaturations and 5 early thrombotic occlusions, respectively. These patients were treated by remedial thrombectomy $(n=5)$ and new access creation $(n=7)$ between the radial artery and the cephalic vein in an upper segment unless they rejected these procedures. Six of those patients were enrolled into the peritoneal 

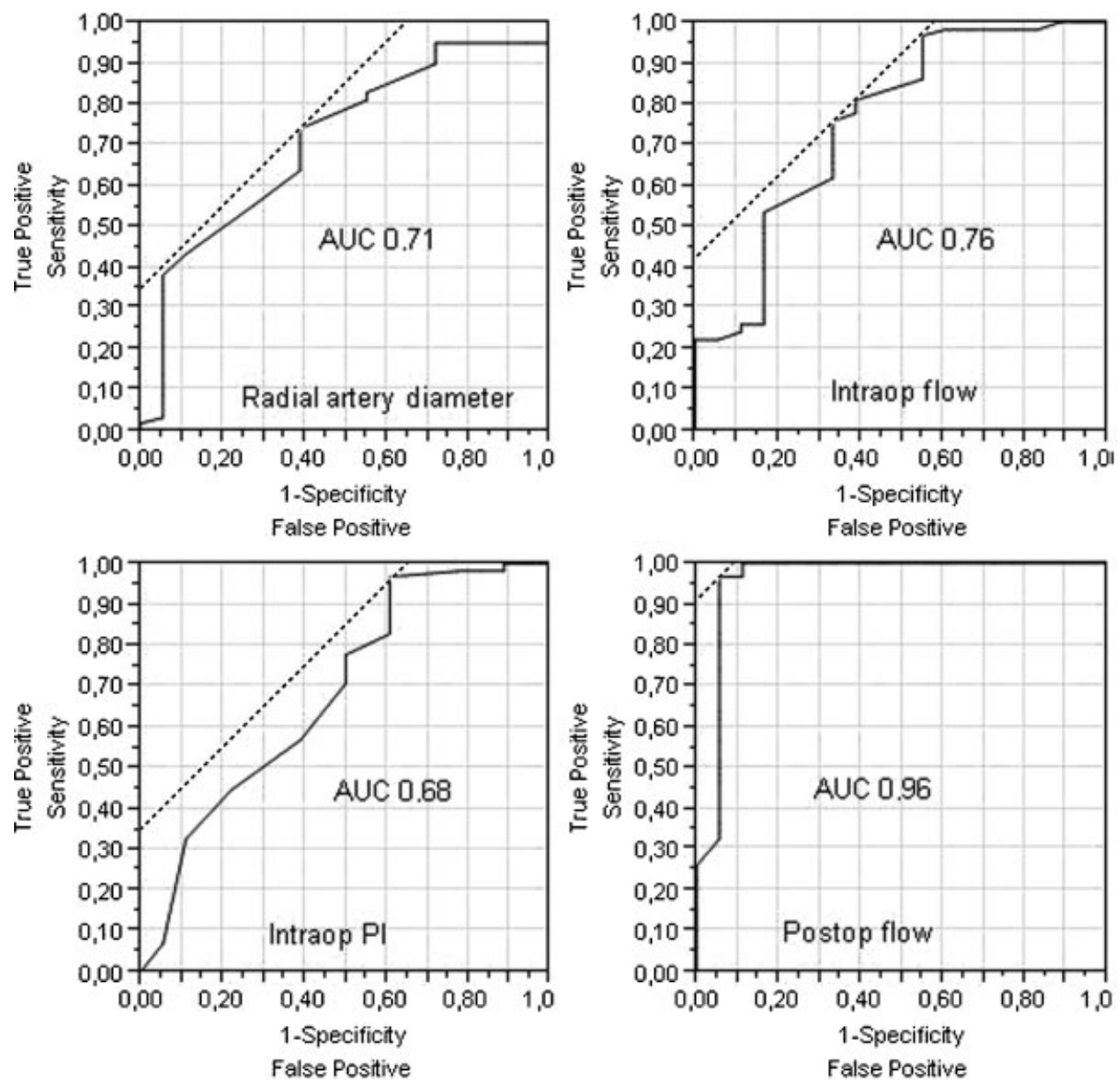

Fig. 1 The ROC. Depicted are the ROC curves for parameters with the highest sensitivity, for example, to predict a nonfunctioning autogenous arteriovenous fistula. AUC, area under the curve; ROC, receiver operating characteristics.

dialysis program because they rejected the repeated surgical access creation and wished more flexibility in determining the location of dialysis at home, at work, or on vacation. In these patients, a short-term alternative dialysis was performed by a tunneled central venous catheter till the beginning of the peritoneal dialysis.

The results of the duplex findings of the AVFs are exposed in - Tables $\mathbf{1}$ and $\mathbf{2}$. The comparison of intraoperative flow and postoperative flow were significantly higher in the functioning group compared with the nonfunctioning group.

There were four variables with significant influence on the AVF function. There was a significant difference about the radial artery diameter $\left(X^{2}=5.23, p=0.02\right)$, intraoperative AVF flow ( $\left.X^{2}=7.09, p=0.01\right)$, intraoperative PI $\left(X^{2}=6.5\right.$, $p=0.01)$, and postoperative AVF flow $\left(X^{2}=16.29, p=0.01\right)$. The cephalic vein diameter $\left(X^{2}=3.41, p=0.08\right)$ was not significant.

To determine a threshold value for the five variables, ROC analyses were performed. These analyses concerned the maximal combination of sensitivity and specificity-the essence of the ROC calculation. The area under the ROC curves demonstrated, at best, a moderate prediction. According to our data, fundamentally predictive requirements for an ideal AVF function were following cut-off values for the diameter of the radial artery $(2.3 \mathrm{~mm})$ and cephalic vein $(2.7 \mathrm{~mm})$, intraoperative AVF flow (113 $\mathrm{mL} / \mathrm{min})$, intraoperative PI (1.4), and postoperative AVF flow (160 mL/min). The complete results of the ROC analyses are displayed in - Table 2 and - Fig. 1.

\section{Discussion}

Remedial or secondary procedures performed on nonfunctioning AVFs may favorably extend patency, but postoperative identification of a compromised conduit has relied on physical examination or unsuccessful first dialysis cannulation. Further imaging techniques evolved for assessing AVF maturation or failure in the postoperative course. But more uniformly applied methods to identify nonfunctioning AVFs and produce a greater overall benefit in patency are lacking.

This study was undertaken to improve the fraction of accesses achieving functional maturation using routine transit-time flow measurement immediately after access construction in the operation theater and early duplex evaluation before discharge. The aim is to identify nonfunctioning AVFs and to select them for remedial intervention to optimize access flow rate and potential access longevity. In this study, we hypothesized that flow characteristics found after access construction and especially with low flow would be at highest risk for nonmaturation and/or thrombosis. Noticing the 
limited published hemodynamic data for access grafts and fistulae, clearly defined velocity thresholds for potential stenosis and dysfunctional conduits are rare. It is worth to mention, that a low value of mean flow detected by transittime flow measurement is not alone an indicator of an imperfect anastomosis, like known from coronary artery bypass grafting. 8 The PI and the waveform characteristics are also important, although the measurement of PI was not employed so frequently in studies dealing with AVFs such as in few of them. ${ }^{9,10}$ The presence of systolic spike and a high PI value is diagnostic. In the present series also, all the AVFs with a PI more than 1.4 had a higher probability for failure. We classified nonfunctioning AVFs as those with low mean flow measured after access construction with accompanying high PI values and low mean flow in the early duplex scanning before discharge.

Our study differs from previous works in one important respect. Previous studies have used hemodynamic parameters such as mean flow to predict AVF function. ${ }^{11-13}$ In contrast to that, we hypothesized that a combined assessment of intraoperative mean flow with PI and early postoperative mean flow could improve the predictive power of AVF maturation, respectively. The influence of the remaining variables such as age, gender, cardiovascular risk factors, and vessel diameter were also investigated as some of them have been characterized as predictors for AVF function in previous studies. $^{14-16}$

In this study of patients undergoing AVF creation, predictors for fistula function and failure emerged as being radial artery diameter, intraoperative mean blood flow, PI, and postoperative mean flow. These variables featured significant correlations between each other. The results are in accordance to data from previous studies. ${ }^{11,17,18}$

One of our objectives was to confirm our hypothesis noninvasively. With transit-time flow measurement, flow volume is directly assessed without any need for additional calculation related to cross-sectional area, so the results are immediately available, easily interpretable, and accurate. $^{3,4,19,20}$ Transit-time ultrasound is diameter-independent and less affected by flow profile than is conventional DUS. Conventional DUS measures point velocity and assumes laminar flow, which is not present in AVFs. ${ }^{3,19}$ In 1998, Johnson et $\mathrm{al}^{3}$ used intraoperative transit-time ultrasound for blood flow measurement in a large number of patients with AVFs and polytetrafluoroethylene grafts. They correlated the blood flow with the final result. Using $320 \mathrm{~mL} / \mathrm{min}$ as a cut-off value, they found a relationship between flow rates and outcome. A high flow ( $320 \mathrm{~mL} / \mathrm{min}$ ) in the AVF predicted a lesser need for reintervention and a superior final survival, independent of demographic variables such as the age, race, sex, and the presence of diabetes. However, they showed that, when the AVF flow was $170 \mathrm{~mL} / \mathrm{min}$, the predicted failure within 90 days approached 56\%. In 2000, Won et al ${ }^{19}$ employed the same transit-time ultrasound for intraoperative blood flow measurements of AVFs and concluded that fistulas with flow less than $160 \mathrm{~mL} / \mathrm{min}$ had a higher failure rate and no correlation between early patency and parameters of diabetes, old age, gender, flow rate of radial artery, and the size of cephalic vein. Just in accordance to referred data, 3,19 our study also points out that the intraoperative mean blood flow is predictive for early failure or the need of reintervention. Nevertheless, the intraoperative PI and postoperative mean flow had even higher sensitivities to predict AVF dysfunction. These data allowed us also to express cut-off values to predict AVF function. Thus, intraoperative mean flow less than $113 \mathrm{~mL} / \mathrm{min}$, PI more than 1.4 , and postoperative mean flow less than $160 \mathrm{~mL} /$ min were predictors for AVF dysfunction. In addition, a radial artery diameter of less than $2.3 \mathrm{~mm}$ was a predictor for AVF dysfunction, but with a lower sensitivity. Interestingly, our cut-off value for the intraoperative mean flow as a predictor for an ideal AVF function was low. ${ }^{21,22}$

Intraoperative blood flow measurement using transittime flow measurement has become routine in AVF surgery in our institution. We consider that high blood flow values during AVF creation decide about the success of operation and imply best short-term patency rates. Thus, when low flow is met during operation, a proximal anastomosis between the radial artery and cephalic vein becomes necessary.

In conclusion, radial artery diameter, intraoperative mean flow, PI, and postoperative mean flow are important predictors of the AVF function. By using the ultrasound transit-time flowmeter, flow information can be gained with ease, accuracy, and reliability. This minimally invasive method could contribute to improve the surgical results further.

\section{Acknowledgment}

We thank Blumenstock Gunnar, MD, Department of Medical Biometry, Eberhard Karls University, Tübingen for his support while calculating the correlation and the ROC analyses.

\section{Disclosures}

No conflict of interest exists for any of the authors.

\section{References}

1 Tordoir J, Canaud B, Haage P, et al. EBPG on vascular access. Nephrol Dial Transplant 2007;22(Suppl 2):ii88-ii117

2 Sidawy AN, Spergel LM, Besarab A, et al; Society for Vascular Surgery. The Society for Vascular Surgery: clinical practice guidelines for the surgical placement and maintenance of arteriovenous hemodialysis access. J Vasc Surg 2008;48(Suppl 5):2S-25S

3 Johnson CP, Zhu YR, Matt C, Pelz C, Roza AM, Adams MB. Prognostic value of intraoperative blood flow measurements in vascular access surgery. Surgery 1998;124(4):729-737, discussion 737-738

4 Beldi G, Bosshard A, Hess OM, Althaus U, Walpoth BH. Transit time flow measurement: experimental validation and comparison of three different systems. Ann Thorac Surg 2000;70(1):212-217

5 Uhlig K, Berns JS, Kestenbaum B, et al. KDOQI US commentary on the 2009 KDIGO Clinical Practice Guideline for the Diagnosis, Evaluation, and Treatment of CKD-Mineral and Bone Disorder (CKD-MBD). Am J Kidney Dis 2010;55(5):773-799

6 Brescia MJ, Cimino JE, Appel K, Hurwich BJ. Chronic hemodialysis using venipuncture and a surgically created arteriovenous fistula. N Engl J Med 1966;275(20):1089-1092 
7 Ziai F, Benesch T, Kodras K, Neumann I, Dimopoulos-Xicki L, Haas $M$. The effect of oral anticoagulation on clotting during hemodialysis. Kidney Int 2005;68(2):862-866

8 D'Ancona G, Karamanoukian HL, Salerno TA, Schmid S, Bergsland J. Flow measurement in coronary surgery. Heart Surg Forum 1999; 2(2):121-124

9 Albayrak R, Yuksel S, Colbay M, et al. Hemodynamic changes in the cephalic vein of patients with hemodialysis arteriovenous fistula.J Clin Ultrasound 2007;35(3):133-137

10 Sivanesan S, How TV, Black RA, Bakran A. Flow patterns in the radiocephalic arteriovenous fistula: an in vitro study. J Biomech 1999;32(9):915-925

11 Lin CH, Chua CH, Chiang SS, Liou JY, Hung HF, Chang CH. Correlation of intraoperative blood flow measurement with autogenous arteriovenous fistula outcome. J Vasc Surg 2008;48(1):167-172

12 Miguel SS, Chow J. Vascular dialysis access flow measurement: early intervention through early detection. J Ren Care 2009;35(4): 185-191

13 Monroy-Cuadros M, Yilmaz S, Salazar-Bañuelos A, Doig C. Risk factors associated with patency loss of hemodialysis vascular access within 6 months. Clin J Am Soc Nephrol 2010;5(10):1787-1792

14 Monroy-Cuadros M, Salazar A, Yilmaz S, McLaughlin K. Native arteriovenous fistulas: correlation of intra-access blood flow with characteristics of stenoses found during diagnostic angiography. Semin Dial 2008;21(1):89-92

15 Malovrh M. Non-invasive evaluation of vessels by duplex sonography prior to construction of arteriovenous fistulas for haemodialysis. Nephrol Dial Transplant 1998;13(1): 125-129

16 Lemson MS, Leunissen KM, Tordoir JH. Does pre-operative duplex examination improve patency rates of Brescia-Cimino fistulas? Nephrol Dial Transplant 1998;13(6):1360-1361

17 Tordoir JH, Rooyens P, Dammers R, van der Sande FM, de Haan M, Yo TI. Prospective evaluation of failure modes in autogenous radiocephalic wrist access for haemodialysis. Nephrol Dial Transplant 2003;18(2):378-383

18 Parmar J, Aslam M, Standfield N. Pre-operative radial arterial diameter predicts early failure of arteriovenous fistula (AVF) for haemodialysis. Eur J Vasc Endovasc Surg 2007;33(1): 113-115

19 Won T, Jang JW, Lee S, Han JJ, Park YS, Ahn JH. Effects of intraoperative blood flow on the early patency of radiocephalic fistulas. Ann Vasc Surg 2000;14(5):468-472

20 Back MR, Maynard M, Winkler A, Bandyk DF. Expected flow parameters within hemodialysis access and selection for remedial intervention of nonmaturing conduits. Vasc Endovascular Surg 2008;42(2):150-158

21 Saucy F, Haesler E, Haller C, Déglise S, Teta D, Corpataux JM. Is intra-operative blood flow predictive for early failure of radiocephalic arteriovenous fistula? Nephrol Dial Transplant 2010; 25(3):862-867

22 Schuman E, Ronfeld A, Barclay C, Heinl P. Comparison of clinical assessment with ultrasound flow for hemodialysis access surveillance. Arch Surg 2007;142(12):1129-1133 